\title{
Tranexamic acid in adult elective orthopaedic and complex spinal surgery: A review
}

\author{
Zakk Walterscheid ${ }^{1}$, Conor O’Neill' ${ }^{1}$ and Jonathan Carmouche ${ }^{1,2 *}$ \\ ${ }^{1}$ Virginia Tech Carilion School of Medicine, USA \\ ${ }^{2}$ Department of Orthopaedic Surgery, Institute for Orthopaedics and Neurosciences, Carilion Clinic, USA
}

\section{Introduction and background}

Tranexamic acid (TXA) was first used in the treatment of postpartum hemorrhage and was popularized for its blood-sparing effects by the CRASH-2 (Clinical Randomization of an Antifibrinolytic in Significant Hemorrhage) trauma trial and the MATTERs (Military Application of Tranexamic Acid in Trauma Emergency Resuscitation) trial examining its use in military trauma resuscitation. Since 2006, the number of articles examining the effects of Tranexamic acid on blood loss and transfusion rates in total joint arthroplasty has increased tenfold. These investigations have led to TXA's wide acknowledgement as an effective means to reduce blood loss and transfusion rates in orthopaedic surgery. Nonetheless, questions still remain regarding dosing, route of administration, and secondary outcomes including, cost savings and hospital length of stay. In this review we will survey the available literature.

TXA is an antifibrinolytic that works to inhibit the plasmin mediated degradation of fibrin. By attaching to the 4-5 lysine-binding site on plasmin, TXA prevents the breakdown of clots formed through activation of the coagulation cascade, thereby reducing blood loss. The drug exhibits triexponential decay with a half life of approximately 2 hours for the terminal elimination phase. The volume of distribution is between nine and $12 \mathrm{~L}$, and urinary excretion accounts for $95 \%$ of elimination [1].

In orthopaedic surgery, TXA is used most notably in the two most common elective orthopaedic procedures necessitating transfusion, total hip (THA) and total knee arthroplasty (TKA) [2]. Blood loss in TKA and THA have been reported to be 1000-2000 $\mathrm{ml} \mathrm{[3-5]} \mathrm{and}$ $700-2000 \mathrm{ml}[6,7]$ respectively. As a result, up to $30 \%$ of patients may require allogenic transfusion $[4,5,7]$. Transfusion rates in complex spine surgery are similarly high and therefore TXA has had growing use in these cases as well.

\section{TXA in total joint arthroplasty}

In total joint surgery, intravenous, topical and oral routes of administration have been reported in the literature. IV administration is the most widely reported route and there is an abundance of evidence supporting its use. Topical administration is touted to reduce total systemic absorption of the drug and is subdivided into intra-articular injection and joint irrigation just prior to closure. Oral administration has been advocated with the primary purported advantages being cost containment and similar bioavailability.

\section{IV and topical use}

For each of the proposed routes of administration, a wide variety of dosing strategies have been reported. Among the many proposed approaches, the most commonly cited IV dosing for TKA and THA is a single dose of 1 gram and an additional dose of 2 grams divided into two individual one gram doses administered at different times. In the published literature the timing of exactly when these doses are administered varies and in several studies is not explicitly explained [819]. The most commonly cited doses for topical TXA are 1.5-3 grams for joint irrigation and 0.5-2 grams for intra-articular injection typically administered following tourniquet let down or immediately before closure [14,17,20-27]. Investigations using these dosing strategies almost universally observe significant decreases in total blood loss, total hemoglobin reduction, and transfusion rates. Transfusion rate reduction is somewhat less ubiquitous, likely owing to differences in each institution's baseline transfusion protocol/threshold in THA and TKA.

Despite the multiplicity of proposed dosing protocols, few prospective studies have directly compared doses for the purpose of optimization. Maniar et al. directly compared both IV and topical dosing strategies in 240 patients undergoing TKA and concluded that a single IV dose is insufficient to significantly reduce total blood loss, and a single topical dose produces a small but significant improvement in total blood loss [28]. Ultimately, the authors favored a triple dosing regimen for maximal reduction of total blood loss and drain output. A major hurdle in the comparison of doses between studies is the lack of uniformity of the available data and specifically, the plethora of outcomes metrics used in the evaluation of TXA's efficacy. The most common metrics include total blood loss, intra-operative blood loss, post operative blood loss, drain output, hemoglobin reduction, and transfusion rates. Meta analyses comparing studies that use the same metrics for efficacy have widely determined TXA use is superior to placebo controls, however such analyses are rarely, if ever, able to compare studies using the exact same dosing regimens and so their conclusions are typically broadly applicable to the use of TXA but do not delve into the optimal IV and or topical dosing strategies other than speculation $[6,7,29-31]$.

\section{Oral use}

In the last few years, the use of oral TXA in total joint arthroplasty has increased both in practice and in the published literature. As in

Correspondence to: Jonathan J. Carmouche, MD, Virginia Tech Carilion School of Medicine; Department of Orthopaedic Surgery, Institute for Orthopaedics and Neurosciences, Carilion Clinic, USA, E-mail: JJCarmouche@carilionclinic. org

Received: March 12, 2017; Accepted: March 16, 2017; Published: March 20 2017 
IV and topical dosing, oral dosing has varied among the handful of studies that have thus far studied oral TXA in arthroplasty. Total dosing, usually divided between pre- and post-operative doses, has been reported as low as 1.95 grams by Fillingham et al. and as high as 6 grams by Bradshaw, et al. [32,33]. The most common metrics reported in the oral TXA literature are net hemoglobin loss and transfusion rates. Fillingham and Irwin found that oral TXA performed comparably to IV TXA in total hemoglobin reduction. Bradshaw and Lee compared oral TXA to placebo and found reduced hemoglobin loss in the oral TXA group [32,34]. Similar to their hemoglobin findings, both Irwin and Fillingham found comparable transfusion rates $(<10 \%)$ between IV and oral TXA. Zohar, one of the first authors to study oral TXA in total joint surgery found a significant decrease in transfusion rates between placebo and oral TXA groups and Bradshaw's prospective study of oral TXA in total knee arthroplasty found no transfusions in the TXA group $[33,35]$. The literature remains somewhat unclear however. By way of example, despite reductions in hemoglobin decrease and total blood loss, Lee did not note significant difference between transfusion rates in oral TXA vs. placebo groups.

The preliminary studies on oral TXA in total joint arthroplasty indicate that it is a promising route of TXA administration for the reduction of total blood loss and cost containment, however as with IV and topical dosing regimens, future investigations are necessary to further evaluate both the optimal dosing protocol and adverse effects in a manner comparable to the other routes of administration.

\section{TXA in spine surgery}

Complex fusions with instrumentation of the spine are associated with long operative times, large exposures and significant blood loss. The extensive dissection and preparation of the vertebrae required for instrumentation and decortication (which exposes large surface area of vascular cancellous bone) for fusion results in high blood loss. In addition, osteotomies for deformity correction are becoming increasingly common and also increase blood loss. As a result, patients undergoing complex spinal surgery often require transfusion [36]. TXA has been widely used within complex spine surgery, from large scoliosis cases to smaller cervical spine procedures, but the majority of the literature on TXA use in adult patients focuses on scoliosis cases. As in total joint arthroplasty, the body of literature examining TXA in spine surgery consistently supports the use of TXA as a means of reducing blood loss and lowering transfusion rates, however the overall effects have been noted to be dose and timing dependent [37].

TXA dosing for spinal procedures varies in volume, timing, and route of administration. There is, however, a preference for intravenous administration over topical administration postulated to be due to the larger incisions seen with spine surgery when compared to total joint arthroplasty. The most common IV dosing involves a $10-20 \mathrm{mg} / \mathrm{kg}$ loading dose with a $1-10 \mathrm{mg} / \mathrm{kg} / \mathrm{h}$ continuous infusion [38]. Topical TXA dosing has not been as extensively researched in spine surgery as in total joint surgery, but common dosing involves $250-500 \mathrm{mg}$ used to irrigate the wound before closure $[39,40]$. The preponderance of evidence has demonstrated TXA to be both safe and effective at reducing blood loss and decreasing transfusion rates associated with spinal surgery [37,38,41,42] (Table 1 ).

\section{Complications}

By its very design, TXA's fibrinolytic mechanism of action promotes the lifespan of clots. This raises the concern for clot-related complications resulting from the completion of Virchow's Triad.
Table 1. Summary of literature guidance on route of administration, dosing and timing of dosing. There is less literature supported consensus with oral dosing and therefore a wide range is given.

\begin{tabular}{|c|c|c|c|}
\hline Procedure & $\begin{array}{c}\text { Route of } \\
\text { Administration }\end{array}$ & Dose & Timing \\
\hline TKA/THA & IV & $\begin{array}{c}1 \text { gram } \\
1 \text { additional 1gram } \\
\text { dose }\end{array}$ & $\begin{array}{c}\text { Loading preop bolus } \\
\text { Post op }\end{array}$ \\
\hline TKA/THA & $\begin{array}{c}\text { Topical (Joint } \\
\text { Irrigation) }\end{array}$ & $\begin{array}{c}1.5-3 \text { gram joint } \\
\text { irrigation }\end{array}$ & Tourniquet let down \\
\hline TKA/THA & $\begin{array}{c}\text { Topical (Intra- } \\
\text { articular) }\end{array}$ & $\begin{array}{c}0.5-2 \text { gram joint } \\
\text { irrigation }\end{array}$ & Injection at closure \\
\hline TKA/THA & Oral & $1.95-6 \mathrm{gram}$ & $\begin{array}{c}\text { 1 hour Preop } \\
6 \text { hours post op }\end{array}$ \\
\hline Spine Surgery & IV & $\begin{array}{c}10-20 \mathrm{mg} / \mathrm{kg} \\
1-10 \mathrm{mg} / \mathrm{kg} / \mathrm{hr}\end{array}$ & $\begin{array}{c}\text { Loading dose } \\
\text { Continuous infusion }\end{array}$ \\
\hline Spine Surgery & Topical & $250-500 \mathrm{mg}$ & $\begin{array}{c}\text { Wound irrigation } \\
\text { prior to closure }\end{array}$ \\
\hline
\end{tabular}

Specifically these patients have stasis from the post-operative state, endothelial injury resulting from surgery, and a hypercoagulable state secondary to TXA administration. Theoretical complications therefore are venous thromboembolism, cerebrovascular incidents, and myocardial infarction. While myocardial infarction, cerebrovascular incidents, superficial and deep tissue infections, wound dehiscence, and GI hemorrhage have been reported in the TXA literature, no correlation with TXA administration during total joint surgery has been demonstrated.

Although the most common side effects of TXA are dizziness and stomach upset, color blindness has been used as an indicator of toxicity. The mechanism of this adverse effect is poorly understood. Nonetheless, as a theoretic result of these patients inability to report a symptom of toxicity, TXA use in color blind individuals is contraindicated. More permanent visual defects have been associated with use of TXA over several days. Discontinuation and prompt opthalmologic evaluation should be obtained with any change in vision. Case reports on visual change with TXA use suggest that discontinuation of TXA and concomitant corticosteroid treatment results in normal visual acuity and fundoscopic exam. Of note, toxicity is highly unlikely at doses used in orthopaedic and spinal surgery.

In order to reduce the likelihood of complications, investigations have employed a number of exclusion criteria, commonly including a history of vascular incident, bleeding problems, renal compromise, and color blindness. In THA and TKA, the most notable complication reported in the literature is venous thromboembolism. The vast majority of orthopaedic TXA studies show no increase in the rate of venous thromboembolism events [29-31,43,44]. Nishihara, et al. is the only study in the recently published literature known to the authors that demonstrated a significant increase in venous thromboembolic events after TXA administration in total joint arthroplasty [18]. An obvious criticism of this study however is that the authors did not employ either mechanical or pharmacological VTE prophylaxis in the care of their patients. DVT prophylaxis is considered standard of care at most institutions. Current literature establishes a multitude of pharmacological VTE prophylactic measures used to prevent associated complication. In the last ten years enoxaparin has been the most commonly cited method of pharmacologic prophylaxis, though an increasing body of literature is accumulating regarding the use of aspirin as primary VTE prophylaxis with promising results.

The potential increase in the risk of thromboembolic events secondary to TXA use in spinal surgery is more contentious, due in 
part to the less robust available body of TXA-spine literature. A metaanalysis by $\mathrm{Li}$, et al. examining six placebo controlled trials found no significant increase in risk of DVT, however other recent meta analyses have been less absolute in their conclusions about thromboembolic risk, citing a relatively small number of patients and investigations included within their scope of analysis that may be insufficient to make definitive claims on DVT and PE risk $[37,45,46]$. Future investigations with larger patient cohorts in the coming years will shed further light on the safety of TXA as a means to reduce blood loss in spinal surgery.

\section{Functional outcomes and cost savings}

The establishment of TXA as an effective means to reduce blood loss and transfusion rates has led a number of authors to investigate the functional outcomes and potential savings associated with its use. Among the most commonly studied functional outcome is length of hospital stay and there remains some debate about TXA's effect on this metric. Both Goyal and Alshryda found small but significant decreases in hospital stay after TKA with use of TXA, whereas Poeran did not conclude that changes in hospital stay were significant [47-49]. Gillette examined costs associated with potential reductions in length of stay found that TXA use in TKA saved \$457 in charges directly related to hospital stay [50]. Studies by Harris and Moskal, et al. revealed up to 96\% cost reduction secondary to TXA use in total joint arthroplasty due to the offset of the high cost of transfusions and their possible complications with the relatively low cost of a dose of TXA ( $\$ 39.14$ per dose) [51,52]. Published cost reduction per patient associated with transfusion costs alone ranges from $\$ 83.73-\$ 380.88$ [17,52,53]. Cost reduction associated with transfusion and increased length of stay ranges from $\$ 730.00-\$ 1235.98[50,54,55]$. Slover and Bosco have postulated that hospitals with a baseline transfusion rate lower than $25 \%$ in total joint arthroplasty may not note financial benefit from the use of TXA, while those with a baseline rate greater than $25 \%$ will experience progressively increasing cost savings [56].

\section{Conclusion}

TXA is widely accepted to decrease blood loss and transfusion rates in total joint arthroplasty and spine surgery. In total joint arthroplasty the most commonly reported routes of administration are IV and topical. Both have shown decrease in EBL and decreased rates of transfusion. More recently, Oral TXA has been shown to have similar efficacy to IV and topical dosing. In spine surgery, IV TXA is the predominant route of administration likely due to its increased ability to provide therapeutic levels over such a large wound surface area.

The risk for increased thromboembolic events from TXA treatment has not been shown to be clinically significant when pharmacological and/or mechanical VTE prophylactic measures are undertaken after total joint surgery. However, certain common exclusion criteria have eliminated a subset of high risk patients, in whom TXA use in total joint arthroplasty has not been effectively studied.

Similarly, the body of literature on TXA in spine surgery is not yet sufficient to make a definitive claim about the risks of DVT and PE. TXA use can lead to significant cost savings associated with decreased transfusions, transfusion related complications, and length of hospital stay, though there is a paucity of data comparing functional outcomes of patients who received TXA to those who did not. Future investigations will build on the current body of knowledge regarding the efficacy of TXA in total joint arthroplasty and complex spinal surgery and these will continue to shed light on the potential for reduction in length of stay and the resulting reduction in healthcare costs.

\section{References}

1. Dunn CJ, Goa KL (1999) Tranexamic acid: a review of its use in surgery and other indications. Drugs 57: 1005-1032. [Crossref]

2. Yoshihara H, Yoneoka D2 (2014) National trends in the utilization of blood transfusions in total hip and knee arthroplasty. J Arthroplasty 29: 1932-1937. [Crossref]

3. Yuan ZF, Yin H, Ma WP, Xing DL (2016) The combined effect of administration of intravenous and topical tranexamic acid on blood loss and transfusion rate in total knee arthroplasty: Combined tranexamic acid for TKA. Bone Joint Res 5: 353-361. [Crossref]

4. Frisch NB, Wessell NM, Charters MA, Yu S, Jeffries JJ, et al. (2014) Predictors and complications of blood transfusion in total hip and knee arthroplasty. J Arthroplasty 29: 189-192. [Crossref]

5. Park JH, Rasouli MR, Mortazavi SM, Tokarski AT, Maltenfort MG, et al. (2013) Predictors of perioperative blood loss in total joint arthroplasty. J Bone Joint Surg Am 95: 1777-1783. [Crossref]

6. Li J, Zhang Z, Chen J (2016) Comparison of efficacy and safety of topical versus intravenous tranexamic acid in total hip arthroplasty: A meta-analysis. Medicine (Baltimore) 95: e4689. [Crossref]

7. Lin ZX, Woolf SK (2016) Safety, efficacy, and cost-effectiveness of tranexamic acid in orthopedic surgery. Orthopedics 39: 119-130. [Crossref]

8. Wind TC, Barfield WR, Moskal JT (2013) The effect of tranexamic acid on blood loss and transfusion rate in primary total knee arthroplasty. J Arthroplasty 28: 1080-1083. [Crossref]

9. Wind TC, Barfield WR, Moskal JT (2014) The effect of tranexamic acid on transfusion rate in primary total hip arthroplasty. J Arthroplasty 29: 387-389. [Crossref]

10. Hideyuki Sasanuma, Hitoshi Sekiya, Kenzou Takatoku, Hisashi Takada, Naoya Sugimoto, et al. (2011) Efficient strategy for controlling postoperative hemorrhage in total knee arthroplasty. Knee Surg Sports Traumatol Arthrosc 19: 921-925. [Crossref]

11. Aguilera X, Martínez-Zapata MJ, Hinarejos P, Jordán M, Leal J, et al. (2015) Topica and intravenous tranexamic acid reduce blood loss compared to routine hemostasis in total knee arthroplasty: a multicenter, randomized, controlled trial. Arch Orthop Trauma Surg 135: 1017-1025. [Crossref]

12. Sepah YJ, Umer M, Ahmad T, Nasim F, Chaudhry MU, et al. (2011) Use of tranexamic acid is a cost effective method in preventing blood loss during and after total knee replacement. J Orthop Surg Res 6: 22. [Crossref]

13. Iwai T, Tsuji S, Tomita T, Sugamoto K, Hideki Y, et al. (2013) Repeat-dose intravenous tranexamic acid further decreases blood loss in total knee arthroplasty. Int Orthop 37: 441-445. [Crossref]

14. Hamlin BR, DiGioia AM, Plakseychuk AY, Levison TJ (2015) Topical versus intravenous tranexamic acid in total knee arthroplasty. J Arthroplasty 30: 384-386. [Crossref]

15. Kim YH, Park JW, Kim JS (2017) Chemical Thromboprophylaxis Is Not Necessary to Reduce Risk of Thromboembolism With Tranexamic Acid After Total Hip Arthroplasty. J Arthroplasty 32: 641-644. [Crossref]

16. Rajesparan K, Biant LC, Ahmad M, Field RE (2009) The effect of an intravenous bolus of tranexamic acid on blood loss in total hip replacement. J Bone Joint Surg Br 91: 776-783. [Crossref]

17. North WT, Mehran N, Davis JJ, Silverton CD, Weir RM, Laker MW (2016) Topical vs intravenous tranexamic acid in primary total hip arthroplasty: a double-blind, randomized controlled trial. J Arthroplasty 31: 1022-1026. [Crossref]

18. Nishihara S, Hamada M (2015) Does tranexamic acid alter the risk of thromboembolism after total hip arthroplasty in the absence of routine chemical thromboprophylaxis? Bone Joint J 97-97B: 458-62. [Crossref]

19. Clavé A, Fazilleau F, Dumser D, Lacroix J (2012) Efficacy of tranexamic acid on blood loss after primary cementless total hip replacement with rivaroxaban thromboprophylaxis: A case-control study in 70 patients. Orthop Traumatol Surg Res 98: 484-490. [Crossref]

20. Wei W, Wei B (2014) Comparison of topical and intravenous tranexamic acid on blood loss and transfusion rates in total hip arthroplasty. J Arthroplasty 29: 2113-2116. [Crossref]

21. Xingming Xu, Xiaofeng Li, Wei Liu, Zhenyu Wang (2015) Longtime soaking of high concentration tranexamic acid in total hip arthroplasty: A prospective randomized controlled trial in 224 patients. Pak J Med Sci 31; 1306-1311. [Crossref] 
22. Chen Y, Chen Z, Cui S, Li Z, Yuan Z (2016) Topical versus systemic tranexamic acid after total knee and hip arthroplasty: A meta-analysis of randomized controlled trials. Medicine (Baltimore) 95: e4656. [Crossref]

23. Patel JN, Spanyer JM, Smith LS, Huang J, Yakkanti MR, et al. (2014) Comparison of intravenous versus topical tranexamic acid in total knee arthroplasty: a prospective randomized study. J Arthroplasty 29: 1528-1531. [Crossref]

24. Tahmasebi MN, Bashti K, Ghorbani G, Sobhan MR (2014) Intraarticular Administration of Tranexamic Acid Following Total Knee Arthroplasty: A Case-control Study. Arch Bone Jt Surg 2: 141-145. [Crossref]

25. Seo JG, Moon YW, Park SH, Kim SM, Ko KR (2013) The comparative efficacies of intra-articular and IV tranexamic acid for reducing blood loss during total knee arthroplasty. Knee Surg Sports Traumatol Arthrosc 21: 1869-1874. [Crossref]

26. Gomez-Barrena E, Ortega-Andreu M, Padilla-Eguiluz NG, Pérez-Chrzanowska H, Figueredo-Zalve R (2014) Topical intra-articular compared with intravenous tranexamic acid to reduce blood loss in primary total knee replacement a double-blind, randomized, controlled, noninferiority clinical trial. J Bone Joint Surg Am 96: 19371944. [Crossref]

27. Lin SY, Chen CH, Fu YC, Huang PJ, Chang JK, Huang HT (2015) The efficacy of combined use of intraarticular and intravenous tranexamic acid on reducing blood loss and transfusion rate in total knee arthroplasty. J Arthroplasty 30: 776-780. [Crossref]

28. Maniar RN, Kumar G, Singhi T, Nayak RM, Maniar PR (2012) Most effective regimen of tranexamic acid in knee arthroplasty: a prospective randomized controlled study in 240 patients. Clin Orthop Relat Res 470: 2605-2612. [Crossref]

29. Wang H, Shen B2, Zeng Y (2014) Comparison of topical versus intravenous tranexamic acid in primary total knee arthroplasty: A meta-analysis of randomized controlled and prospective cohort trials. Knee 21: 987-993. [Crossref]

30. Moskal JT, Capps SG (2016) Meta-analysis of intravenous tranexamic acid in primary total hip arthroplasty. Orthopedics 39: e883-892. [Crossref]

31. Chen S, Wu K, Kong G, Feng W, Deng Z, et al. (2016) The efficacy of topical tranexamic acid in total hip arthroplasty: a meta-analysis. BMC Musculoskelet Disord 17: 81. [Crossref]

32. Fillingham YA, Kayupov E, Plummer DR, Moric M, Gerlinger TL, et al. (2016) The james a. rand young investigator's award: a randomized controlled trial of oral and intravenous tranexamic acid in total knee arthroplasty: The same efficacy at lower cost? J Arthroplasty 31: 26-30. [Crossref]

33. Bradshaw AR, Monoghan J, Campbell D (2012) Oral tranexamic acid reduces blood loss in total knee replacement arthroplasty. Current Orthopaedic Practice 23: 209-212.

34. Irwin A, Khan SK, Jameson SS, Tate RC, Copeland C, et al. (2013) Oral versus intravenous tranexamic acid in enhanced-recovery primary total hip and knee replacement: results of 3000 procedures. Bone Joint J 95-95B: 1556-61. [Crossref]

35. Zohar E, Ellis M, Ifrach N, Stern A, Sapir O, Fredman B (2004) The postoperative blood-sparing efficacy of oral versus intravenous tranexamic acid after total knee replacement. Anesth Analg 99: 1679-1683. [Crossref]

36. Tate DE Jr, Friedman RJ (1992) Blood conservation in spinal surgery. Review of current techniques. Spine (Phila Pa 1976) 17: 1450-1456. [Crossref]

37. Yang B, Li H, Wang D, He X, Zhang C, et al. (2013) Systematic review and metaanalysis of perioperative intravenous tranexamic acid use in spinal surgery. PLoS One 8: e55436. [Crossref]

38. Cheriyan T, Maier SP 2nd, Bianco K, Slobodyanyuk K, Rattenni RN, et al. (2015) Efficacy of tranexamic acid on surgical bleeding in spine surgery: a meta-analysis. Spine $J$ 15: 752-761. [Crossref]

39. Krohn CD, Sørensen R, Lange JE, Riise R, Bjørnsen S, Brosstad F (2003) Tranexamic acid given into the wound reduces postoperative blood loss by half in major orthopaedic surgery. Eur J Surg Suppl 57. [Crossref]

40. Saberi H, Miri SM, Poordel Namdar M (2010) The effects of topically applied tranexamic acid on reduction of post-laminectomy hemorrhage. Tehran University Medical Journal 68: 527-533

41. Yuan QM, Zhao ZH, Xu BS (2017) Efficacy and safety of tranexamic acid in reducing blood loss in scoliosis surgery: a systematic review and meta-analysis. Eur Spine J 26: 131-139. [Crossref]

42. Winkelstein BA, McLendon RE, Barbir A, Myers BS (2001) An anatomical investigation of the human cervical facet capsule, quantifying muscle insertion area. $J$ Anat 198: 455-461. [Crossref]

43. He P, Zhang Z, Li Y, Xu D, Wang H (2015) Efficacy and safety of tranexamic acid in bilateral total knee replacement: A meta-analysis and systematic review. Med Sci Monit 21: 3634-3642. [Crossref]

44. Zhang H, Chen J, Chen F, Que W (2012) The effect of tranexamic acid on blood loss and use of blood products in total knee arthroplasty: a meta-analysis. Knee Surg Sports Traumatol Arthrosc 20: 1742-1752. [Crossref]

45. Zhi-Jun Li, Xin Fu, Dan Xing, Hua-Feng Zhang, Jia-Cheng Zang, Xin-Long Ma (2013) Is tranexamic acid effective and safe in spinal surgery? A meta-analysis of randomized controlled trials. Eur Spine J 22: 1950-1957. [Crossref]

46. Zhang F, Wang K, Li FN, Huang X, Li Q, et al. (2014) Effectiveness of tranexamic acid in reducing blood loss in spinal surgery: a meta-analysis. BMC Musculoskelet Disord 15: 448. [Crossref]

47. Goyal N, Chen DB, Harris IA, Rowden N, Kirsh G, et al. (2016) Clinical and financial benefits of intra-articular tranexamic acid in total knee arthroplasty. J Orthop Surg (Hong Kong) 24: 3-6. [Crossref]

48. Alshryda S, Mason J, Sarda P, Nargol A, Cooke N, et al. (2013) Topical (intraarticular) tranexamic acid reduces blood loss and transfusion rates following total hip replacement a randomized controlled trial (TRANX-H). J Bone Joint Surg Am 95: 1969-1974. [Crossref]

49. Poeran J (2014) Tranexamic acid use and postoperative outcomes in patients undergoing total hip or knee arthroplasty in the United States: retrospective analysis of effectiveness and safety. BMJ-British Medical Journal 349: g4829-g4829.

50. Gillette BP, Maradit Kremers H, Duncan CM, Smith HM, Trousdale RT, et al. (2013) Economic impact of tranexamic acid in healthy patients undergoing primary total hip and knee arthroplasty. J Arthroplasty 28: 137-139. [Crossref]

51. Harris RN, Moskal JT, Capps SG (2015) Does tranexamic acid reduce blood transfusion cost for primary total hip arthroplasty? A case-control study. J Arthroplasty 30: 192195. [Crossref]

52. Moskal JT, Harris RN, Capps SG (2015) Transfusion cost savings with tranexamic acid in primary total knee arthroplasty from 2009 to 2012. J Arthroplasty 30: 365-368. [Crossref]

53. Tuttle JR, Ritterman SA, Cassidy DB, Anazonwu WA, Froehlich JA, et al. (2014) Cost benefit analysis of topical tranexamic acid in primary total hip and knee arthroplasty. $J$ Arthroplasty 29: 1512-1515. [Crossref]

54. Chimento GF, Huff T, Ochsner JL Jr, Meyer M, Brandner L, et al. (2013) An evaluation of the use of topical tranexamic acid in total knee arthroplasty. $J$ Arthroplasty 28: 7477. [Crossref]

55. McGoldrick NP, O’Connor EM, Davarinos N, Galvin R, Quinlan JF (2015) Cost benefit analysis of the use of tranexamic acid in primary lower limb arthroplasty: A retrospective cohort study. World J Orthop 6: 977-982. [Crossref]

56. Slover J, Bosco J (2014) Cost analysis of use of tranexamic Acid to prevent major bleeding complications in hip and knee arthroplasty surgery. Am J Orthop (Belle Mead NJ) 43: E217. [Crossref]

Copyright: (C2017 Walterscheid Z. This is an open-access article distributed under the terms of the Creative Commons Attribution License, which permits unrestricted use, distribution, and reproduction in any medium, provided the original author and source are credited. 